\title{
How to negotiate with dominant suppliers? A game-theory perspective from the indus- try
}

\author{
Miguel Mediavilla, Kepa Mendibil and Olga Rivera
}

Recibido: 27 de Julio de 2018 / Aceptado: 29 de Diciembre de 2018

\begin{abstract}
The negotiation with dominant suppliers usually drives to locked-in situation in which buyers have no choice but to accept the given conditions. Commonly found in the industry, there is a need to provide new insights to practitioners to leverage competition. Specifically, researchers apply and test concepts from Game-Theory in a real supplier selection process in the port cranes industry. Our research shows that existing literature in Game-Theory is mostly descriptive, very focused on auctions and has still limitations regarding the design, application and impact of these supplier selection concepts. Therefore, it is presented one of the first field studies presenting the application of game-trees and backward induction (tools from Game-Theory) for the design and execution of a real bargaining, including the hows and whys of our decisions. The results suggest that using Game-Theory can enhance the chance to have better negotiation outcomes by predicting the possible outcomes and prescribing the best fitting game to be design in order to increase competition among suppliers.
\end{abstract}

\section{Keywords}

Purchasing; Game-theory; negotiation; supplier selection

\section{Introduction}

'How can we leverage competition if we have dominant suppliers?' This is the question that managers from the case company (a European manufacturer of harbour cranes) of this paper asked to the research team while working together in the development and deployment of purchasing strategies. Precisely, this paper stems from an industrial challenge to leverage competition: the second highest procured category (Cat-E) -in terms of total product costs- of the case company had a dominant supplier (supplier-S). This Supplier-S had been successively imposing prices levered on its position as a renowned multinational company acting worldwide and with an estimated European market share for the Cat-E of more than $60 \%$ of the new harbour crane projects. Since the case company needed to reduce costs and supply-risk to satisfy the market needs of their clients, they were forced to look for an innovative approach to conduct their supplier selection process for its Cat-E.
In fact, to leverage competition among suppliers is not a new challenge to industry since it is widely accepted that purchasing policies can significantly improve sales margins through realizing substantial cost savings and provide an opportunity for firms to contribute to a position of competitive advantage (Van Weele 2009). At a strategic level, industry has generally taken over several purchasing methods (Kraljic 1983) when executing category management and purchasing portfolio activities (Gelderman and Van Weele 2005; Monczka and others 2008; Tassabehji 2010). Whilst the use of some of these methods can help purchasing practitioners in developing suitable strategies, the deployment of specific purchasing policies and practices from the strategic to the tactical purchasing level is primarily deployed on the tactical purchasing process: the activities related to the definition of purchasing specifications, search and selection of the appropriate suppliers, and the preparation and execution of any supplier negotiations in order to establish and sign the legal contract (Van Weele 2009). Among these activities, supplier selection is considered a critical task that can act as a strategic contributor to the firm (Krause, Pagell, and Curkovic 2001) although it is also considered as a potential source of complex and difficult decision making challenges (Huang and Keskar 2007; Yigin et al. 2007).

Therefore, this paper discusses if the supplier selection can benefit from a more systematic application of Game-Theory (GT), which can provide new perspectives to these situations (e.g. be utilised for prediction of the negotiations and therefore be able to better design these beforehand). Literature review shows that there is limited knowledge about the design 
and application (hows) of supplier selection processes based on GT (Hawkins, Randall, and Wittmann 2009; Tassabehji 2010; Schoenherr et al. 2012; Hsin Chang, Tsai, and Hsu 2013; Spina et al. 2013) with current research being mainly descriptive or prescriptive (whats) in nature. Additionally, to the best of our knowledge there are scarce examples of empirical GT applications in bargaining within purchasing negotiations. Hence, the aim of this paper is twofold: first, it will provide new insights about the design of a supplier selection process -specifically the usage of game-trees and backward induction for bargaining- based on GT. Second, it will show evidence of the impact that a more systematic application of GT can have on the effectiveness of the supplier selection process, even when there are dominant suppliers in the category.

\section{Fundamentals of GT and its applica- tion to supplier selection}

Since the 1950s GT has become an important field of study and is now an important methodology for researchers in many disciplines. GT is mainly used on situations in which players have conflicting interests. In other words, GT is a set of analytical tools designed to help us understand when it is observed how decision-makers interact, assuming that these pursue well-defined exogenous objectives (i.e. they are rational) and take into account their knowledge or expectations of other decision-makers' behaviour (i.e. they reason strategically). These interactions are the games and are "a description of strategic interactions that include the constraints on the actions that the players can take and the players' interest but does not specify the actions that the players do take" (Osborne \& Rubinstein 1994).

Every game is played by a set of rules (Dutta 1999), which specify who is playing (players), what they are playing with (strategies), when each player gets to play (what is the sequence) and how much they stand to gain or lose (payoffs). The games can be classified depending on three dimensions:

(1) Noncooperative vs. cooperative games: a player is the basic entity in all GT models, whether an individual (noncooperative) or a group of individuals (cooperative) are deciding.

(2) Strategic vs. Extensive games: timing of decision making, whether it is made simultaneously (strategic games) or consecutively (extensive games) by players.

(3) Perfect vs. Imperfect information: if the players have the full information about each others' moves (perfect information) or not (imperfect information).

Any game has solutions that are described as "a systemic description of the outcomes that may emerge in a family of games" (Osborne and Rubinstein 1994). GT suggests reason- able solutions for classes of games and examines their properties, i.e. may be used for explanation, prediction or prescription in various circumstances (Dixit and Skeath 1999). Mechanism Design theory (2007 Nobel prize in Economics) is an evolution of GT and goes a step further by selecting the optimal rules of the game (Börgers 2015). Therefore, the authors argue that if a buyer is able to design a supplier selection process with a sufficient number of qualified suppliers (players) that compete in a predefined process (sequence) in order to win a pre-established award (payoff), then the possible decisions from suppliers (strategies or choices) could be influenced by the buyer's interest - an interesting angle that cannot be easily covered by other scientific approaches.

As a field of research within GT, bargaining theory is focused on explaining how a surplus, generated in every economic transaction, will be divided by predicting the price at which the transaction will take place. If there is more than one course of action for all individuals and there is a conflict over which course of action to pursue then, some form of negotiation over how to resolve the conflict is necessary. Regarding the application of GT to supplier selection, two generic approaches for supplier selection are often identified within the literature: negotiation and auctioning. Bargaining Theory (typically applied to negotiations) and Auction Theory are based on the principles of GT, and they aim to promote competition or cooperation between suppliers to enhance the results of the supplier selection process (Wyld 2011; Chaturvedi, Beil, and Martínez-de-Albéniz 2014). When applying bargaining theory to the supplier selection process, GT suggests the use of the extensive form games, i.e. a detailed description of the sequential structure of the decision problems encountered by players in a strategic situation, in which players can have perfect or imperfect information. For their analysis, game-trees are utilised and the method for solving is known as rollback or backward induction (Dixit and Skeath 1999).

The literature covering the empirical application of GT for bargaining and negotiation for supplier selection in purchasing was evaluated by searching combinations of such terms as "bargaining", "game-theory", "game-tree", "backward-induction", "purchasing", "procurement", "supplier selection" or "negotiation" in the major databases (Inform/ ProQuest, EBSCO Host, and Science Direct). Initially, a selection of articles from this search was done, including new sources identified by tracing the references included in these articles (Webster and Watson 2002). That work was continued till additional searches gave no additional works addressing relevant issues. The usage of this process did not allow the researchers to find relevant field studies utilising game-trees and backward induction when designing and executing a game (supplier awarding/selection) with participation of practitioners.

Therefore -and to the best of our knowledge- it can be stated that empirical evidences of GT application for bargaining, by utilising game-trees and backward induction, during the 
design and execution of supplier selection in purchasing are limited. Neither academics nor practitioners have discussed thoroughly field cases that could provide valuable insights for this research path. Therefore, it is proposed the following research question: How can GT, specifically the usage of game-trees and backward induction for bargaining, be systematically applied to enhance the effectiveness of the negotiation process in supplier selection?

Providing more details on the actual works on GT in supplier selection will be of great interest to both practitioners and academics in purchasing management. Research that empirically tests the outcome predictions of GT models would enable the refinement of existing theories and resulting consequences (Mithas and Jones 2007). Further empirical research would also help practitioners in the design of more effective selection processes and integrate those into their procurement strategies for improving firm's performance (Weele and Raaij 2014).

\section{Methodology}

Action research (AR) has been selected as the methodological basis for this work. The aim of AR is to contribute to the academic research and provide solutions to practitioners' problems, with the researcher(s) being actively involved in the process of change (Susman and Evered 1978; Eden and Huxham 1996; Coughlan and Coghlan 2002; Vignali and Zundel 2003).

Precisely, that research was carried out in collaboration with a European manufacturer of harbour cranes that has been operating for over 50 years. The case company has been highly impacted by container handling industry evolution, which has gone through significant changes as a result of globalisation, high volume of maritime transport and increased levels of standardisation. Nowadays, the crane system market is largely dominated by a Chinese organisation having $70 \%$ market share, with the remaining 30\% being shared amongst smaller manufacturers. Due to the increased pressure to provide engineer-to-order solutions on a shorter lead time, lower cost and higher quality, the case company launched an ambitious strategic procurement plan for the period 2013-2016. This strategic procurement plan contained a strong focus on achieving tangible improvements in the procurement process by reducing the final costs of the parts acquired from their suppliers. The challenge described in this paper stemmed from the main working fields of the strategic procurement plan, namely to increase competition (explicitly to have significant cost reduction) in the purchasing category Cat-E that had a dominant Supplier-S. A rapid analysis of the costs regarding Cat-E along the period 2003-2012 showed that comparable projects had always maintained or increased their costs. Therefore, the company wanted an innovative ap- proach for an effective negotiation, which provided an interesting case for academics in order to develop, structure and test new knowledge.

AR generates emergent theory, which in words of Coughlan and Coghlan (2002, p.229) "emerges through the unfolding of a series of events as the designated issue is confronted and attempts at resolution by the members of the organisation with the help of the action researcher". During AR studies the cycle of planning-taking action- observation-evaluation occurs several times (Susman and Evered 1978; Perry and Zuber-Skerritt 1992; Coughlan and Coghlan 2002). This continuous inquiry-reflection process that characterises AR means that learning is gained in action: since operations management research often requires learning from application, AR has become a more widely used approach for this discipline (Westbrook 1995; Coughlan and Coghlan 2002).

Also recent literature on the field of purchasing recognises that AR helps to embrace the "complexity of buyer-supplier relationships, generating important theoretical insights and relevant managerial implications" (Maestrini et al. 2016). To be out in the field and in close contact with the environments being studied can enhance any theoretical proposal (Handfield and Melnyk 1998), especially valid for GT applied to supplier selection as it is still at the stage of theory-building. Additionally, in the field of applied GT researchers have often used laboratories. This approach has considerable limitations since real world initiatives are significantly more complex and as such field studies are necessary to complement insights from laboratories (Mithas and Jones 2007).

Therefore, the researchers embarked on the project with the aim to design and support the execution of a GT based negotiation. The project team included researchers and key persons of the company (Purchasing Director, Purchasing Expert, Innovation Director, Logistics Director and Chief Electrical Engineer). The practitioners involved made possible a continuous review of the actions that were being taken throughout the process, which is a critical element to enhance the validity of AR studies. In addition, after completing the supplier selection process, several semi-structured interviews and group discussions with the management were conducted. The project team that carried out the game with Supplier-S had also a separate session to reflect on the process and discuss the learnings from the novel experience.

The main data collection and analysis period lasted for 5 months during 2013. The data collection consisted of records from direct participation in meetings during the entire design and execution of the negotiation process, semi-structured interviews and company internal documentation. The lead researcher was the main responsible for the design the supplier selection process and played an advisory role during the onsite negotiation with Supplier-S. 


\section{Developing \& implementing a GT based supplier selection process}

Our process (table 1) aimed to support the case company to get a more efficient result of their supplier selection. It allowed the case company to better design the negotiation strategies, predict the outcomes and get more competitive bids. Key pieces of existing research have been utilised, being stage 4 and 5 our key contribution. It has been detailed which key decisions to make and how apply GT elements to properly execute the game (i.e. bargaining with Supplier-S of the Cat-E in the project belonging to Client-P):
Table 1 Process for designing a GT based supplier negotiation process

\begin{tabular}{ccc}
\hline Stage & Purpose & What to do \\
\hline
\end{tabular}

1) Analyze strategic importance \& complexity of supply market for a given category
Assess purchasing category, evaluate purchasing power vs important suppliers and implicit risks in the supply
1) Quantitative data gathering, e.g. No. of released suppliers for the category, No. of potential suppliers not released yet, purchasing volume (PVO) per supplier and the category; 2) 2. Supply category according to Kraljic's matrix by using either the consensus, one-byone or weighted-factor score method; 3) Plot results

$\begin{array}{ll}\text { 2) Evaluate supply cat- } & \begin{array}{l}\text { Identify most suitable generic } \\ \text { egory and generic pur- } \\ \text { strategies for each category \& }\end{array} \\ \text { possing strategies } & \begin{array}{l}\text { strategies } \\ \text { steneric purchasing }\end{array}\end{array}$

1) Understand generic purchasing strategies per quadrant; 2) Decide what strategy to utilize for the category. Asses the relative power buyer-supplier and its impact on the strategy selection; 3) Discuss alignment of the selected category strategy with purchasing strategy for the Kraljic's Matrix

3) Evaluate negotiating conditions for category

The definition of the current situation of the category regarding the competitiveness
1) Evaluate number of released suppliers that could take part in awarding process; 2) Gain commitment regarding awarding from all decision making areas; 3) Assess level of attractiveness of potential contract for supplier; 4) Set awarding target (e.g. price reduction) and prepare a possible prediction for the awarding; 5) Preselect a group of suppliers and send a Request For Quotation (RFQ) that can qualify them for the awarding process

$\begin{array}{ll}\text { 4) Negotiation game } & \begin{array}{l}\text { Define the negotiation game, i.e. } \\ \text { players, rules and information }\end{array} \\ \text { design } & \end{array}$

1) Specify which suppliers will be invited to the game (players) based on the RFQ responses; 2) Design game details on strategy, game sequence and information: (a) cooperative or non-cooperative game, (b) strategic game (all decisions at the same time) or extensive game (one decision after the other) and (c) information is perfect or imperfect and how it will be given to players; 3) For extensive-form game, develop decision tree and apply backward induction (see e.g. Osborne and Rubinstein (Osborne, Rubinstein 1994) for predicting possible results and adapt the game design; 4) For auctions: decide auction type based on e.g. Dutta (1999), taking into account the prior RFQ received; 5) Provide management with detailed information to ensure commitment required with this stage of the process

\begin{abstract}
5) Negotiation game execution

The execution the negotiation game as defined in stage 4
\end{abstract}

1) Develop standard contract with price \& condition liability for suppliers and get signatures; 2) Communicate negotiation game rules to players (suppliers), according to the game design developed in the stage 4;3) Execute game exactly as defined; 4) Close game (awarding) and assign the item to the winning supplier.

\section{Stage 1 \& Stage 2 \& Stage 3}

The researchers conducted meetings and semi-structured interviews with the company's top management and collected quantitative information to support our initial evaluation of the negotiation. The purchasing category was then evaluated using Kraljic's purchasing portfolio matrix (1983) (figure 1) by the consensus method (Gelderman and Van Weele 2003). Outcome was to position the Cat-E in the Strategic quadrant. 
Figure 1 Kraljic's matrix and purchasing strategies (Gelderman and Van Weele 2003).

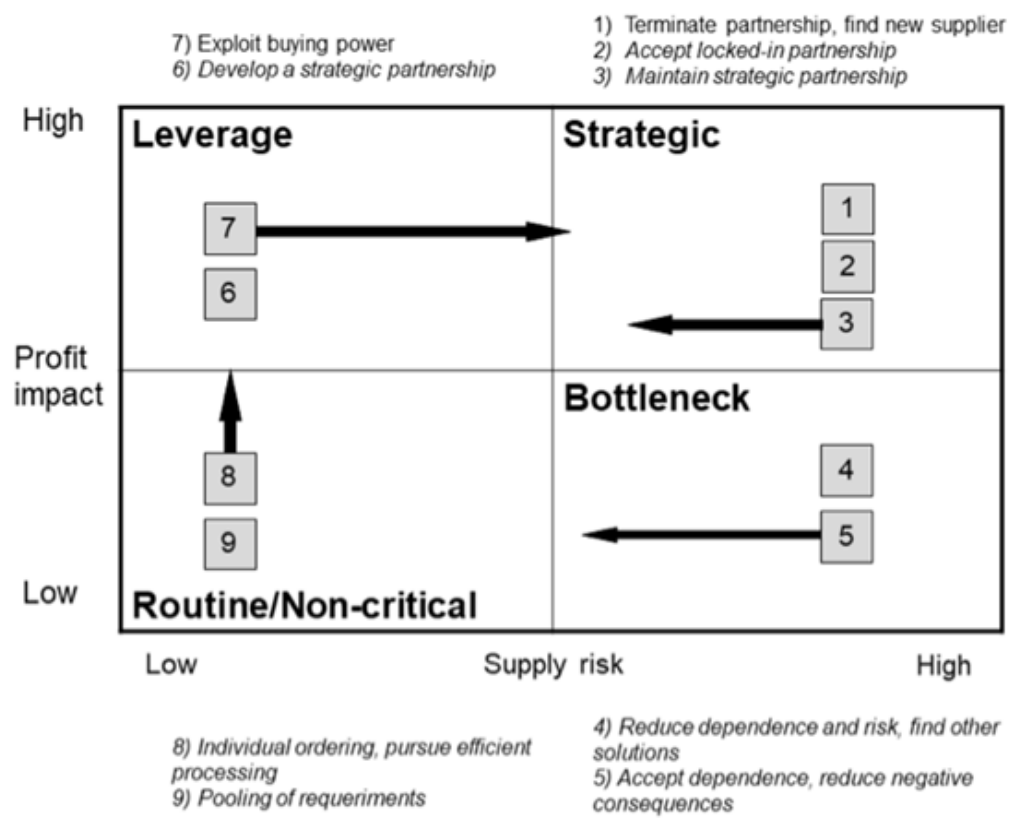

(2) extensive-form game (i.e. decisions are made consecutively)

(3) with imperfect information.

If Supplier-A had participated in the awarding process, a strategic form game could have been designed, e.g. Supplier-A and -S competing in an auction. An auction could have been developed to make Supplier-S to compete against itself, but it was considered risky. Thus, the utilisation an extensive form game was deemed to be more adequate, since this allowed to have a structured negotiation and the introduction of other alternatives for certain part of the negotiation if needed and technically feasible (denote e.g. strategy-b in figure 2, when the scope of the Supplier-S is narrowed). The extensive form negotiation design was modelled utilizing a game tree (figure 2) and the analysis was done via backward induction. The imperfect information was mainly focused on the pay-off structure, the technical feasibility and risk evaluation of the alternative strategies to follow.

The most challenging -and also critical to success- task while modelling the negotiation through the game-tree was the evaluation of the expected payoff for the Supplier-S. This task was led by the Innovation Director, Chief Electrical Engineer and the Purchasing Director of the case company, with the methodical support of the Lead Researcher. This work implied a detailed value analysis and reverse engineering of the product supplied by Supplier-S in the Cat-E. The analysis provided a deep understanding of the product functions and the related costs drivers. In addition, very detailed cost estimations of the production costs of the Supplier-S were carried out. For that purpose, the case company integrated selected sub-suppliers of the products contained in the Cat-E and acted as a potential future manufacturer ${ }^{2}$.

\footnotetext{
${ }^{2}$ The results from that analysis made the case company to launch a parallel initiative to insource the manufacturing competencies of the Cat-E. In the period mid-2015 to mid-2016 the very first crane with an own product of the Cat-E was sold, manufactured and installed.
} 
Figure 2 Game tree of the case study

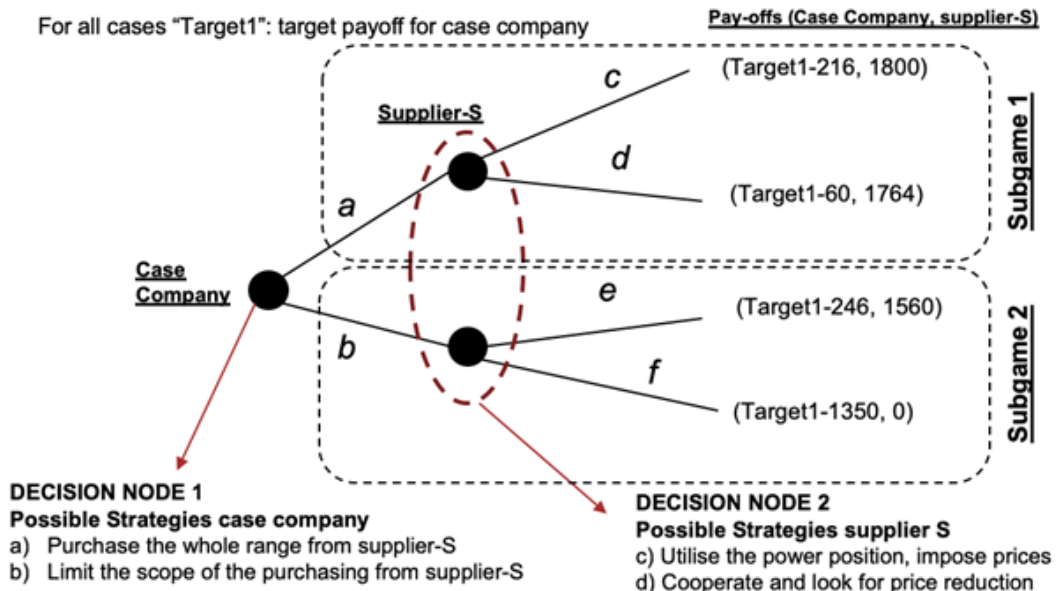

e) Accept the new (narrower) project scope and deliver to case company f) Reject the new (narrower) project scope and stop any delivery

The historical negotiation environment on the Cat-E during the previous years is modelled on the upper branch (subgame 1) of the game-tree. Here, if supplier-S were the unique one competing, the case company had only the chance to purchase the whole range from Supplier-S (decision node 1 and strategy-a) and consequently, Supplier-S could use its power position and impose prices (decision node 2 and strategy-c) or to cooperate and look for a price reduction (decision nodes 2 and strategy-d). In this specific case, GT proposes to solve the situation via backward induction, starting from the last decision node and going back to the first decision node considering the possible payoffs (the higher payoff for any player is the better):

- If Supplier-S decides on strategy-c they would have a payoff of 1800 whereas if they choose strategy-d the payoff would be 1764. If Supplier-S acts rationally and there is no incentive to change the decision based on the available pay-offs, GT predicts that Supplier-S will always adopt strategy-c. On the other hand, if the case company analyses the resulting payoffs from the strategies-c and $-d$, the case company would always prefer the Supplier-S to choose strategy-d (pay-off of Target1-60) than strategy-c (pay-off of Target1-216).

- In conclusion, the prediction of that subgame 1 will always finish with Supplier-S choosing strategy-c and case company accepting that situation since they have no other alternative in the decision node 1 . In fact, that was the real environment happening during the period 2003-2012, confirmed by the analysis that were carried out and the preparatory meetings with the case company.

Because of this initial analysis, the research team proposed the creation of an additional alternative in the decision node 1. If Supplier-A had been part of the negotiation process, it would have allowed to outline different scenarios in the decision node 1 , but since they were vetoed from the process it was necessary to create an additional alternative. This was the creation of the strategy-b that proposed to limit the purchasing scope from Supplier-S. The strategy-a was really the best possible strategy for the case company in terms of pay-off (best case Target1-60, worst case Target1-216), but strategy-b was introduced to create a credible threat on Supplier-S: the aim was to create an option in which Supplier-S could have a worse payoff than in any other possible outcome within strategy-b. This meant that the case company had an additional strategy in the first decision node, which also created more possible strategies for the Supplier-S in the second decision node. Analysing the complete game tree by means of backward induction suggests:

- If it is started by analysing the second decision node, Supplier-S would have two possible scenarios. The subgame 1 is choosing between strategy-c and $-d$, and it has been already predicted that Supplier-S will always choose strategy-c.

- The subgame 2 makes the Supplier-S to choose between strategy-e and -f. Analysing the pay-offs, Supplier-S will always choose strategy-e, since strategy-f will provide no pay-off as it means not supplying to the case company. Therefore, it can be predicted that if the case company selects the strategy-b, Supplier-S will be forced to choose strategy-e.

- The analysis enables the prediction that choosing strategy-b in node 1 , and strategy-e in node 2 is clearly not the most efficient solution for both parties since the strategy-a in node 1 , and strategies-c and $-d$ in node 2 have better pay-offs for all. If the Supplier-S has the chance to choose between strategy-c and $-\mathrm{d}$, the first will be always selected, but this has a lower pay-off for the case company. As a result, the game structure should be modified to eliminate strategy-c being an option. Researchers and case company developed a draft contract specifying that Supplier-S is committed to reduce the economical offer if the whole project is 
assigned: thus, encouraging Supplier-S to choose strategy-d if they wanted to discard strategies-e and -f, which had lower pay-offs for Supplier-S. The contract also included additional penalty clauses for delays and late technical modifications, which should further encourage Supplier-S to collaborate in price negotiations (strategy-d).

\section{Stage 5: Game execution}

The negotiation process strictly followed the design to avoid having new variables and strategies that had not been taking into account previously. Case company introduced strategy-b and communicated to Supplier-S. Under this strategy-b, the model predicts that Supplier-S would have chosen the-e strategy even if this is not the most efficient option for both parties. This created a threat on the Supplier-S that led that supplier to reconsider strategy-a and take a more collaborative approach when negotiating the price. The power position strategy-c suddenly becomes irrelevant or not real. However, Supplier-S offered strategy-d to the case company, after having received the communication that the case company went for the strategy-b, and this was accepted by the case company. Interesting insights emerged during the execution and helped us to strengthen our assumptions and predictions: e.g. Purchasing Director forgot his cell phone the day after the case company communicated that they were going to adopt strategy-b. Finally, CEO of Supplier-S called to CEO of the case company and this gave us valuable information that supplier-S had not been expecting the strategy-b and that it was not a good solution for that supplier-S. It supported our prediction that Supplier-S would cooperate and propose strategy-d.

\section{Results and conclusions}

The validity of the findings and the quality of the research should be carefully evaluated by utilising criteria already identified in the literature: practical relevance, usefulness, theoretical novelty, applicability of the findings in other situations and research rigour (Kasanen, Lukka, and Siitonen 1993; Eden and Huxham 1996; Coughlan and Coghlan 2002). This is particularly important as response to the common critique of AR "to brand it as consulting masquerading as research" (Coughlan and Coghlan 2002), as well as its lack of repeatability and generalisability since focus it is used on solving specific problem in a given context.

Action Research requires to demonstrate the practical relevance and usefulness of the outcomes in a given context (Susman and Evered 1978; Kasanen, Lukka, and Siitonen 1993; Eden and Huxham 1996; Coughlan and Coghlan 2002). In the presented work, the case company had a clear target derived from a practical problem, i.e. get significant cost saving in the Cat-E by using innovative approaches when conducting the supplier selection process for that category. The design and executing of the negotiation carried out with the Supplier-S has shown that the case company has got cost saving in the Cat-E for the project of the Client-P. Even though the Target1 has not been achieved, the outcome was Target1-60 and it has brought a significant cost reduction compared to the previous Target1-216 scenario. Moreover, having a systematic processes to apply GT to the supplier selection process could support practitioners since "(they) did not always know the rationale for the choice of parameters or how that might have affected cost savings" (Mithas and Jones 2007).

The project team members from the case company were highly satisfied since they could redirect the business relation with supplier-S after a long period of locked-in relation. The Target1-60 was considered as a very good result by the $\mathrm{CEO}$ and the Purchasing Director of the case company. In fact, the research team was invited to design and execute a similar supplier selection process as soon as this research was finished. The feedback sessions with the case company showed the following key comments from practitioners:

- The design phase of the negotiation has provided a tremendous transparency for all the project team members, even if they had different background or even local interests related to their department. The game-tree has been a powerful tool to align all the team (especially the engineering and purchasing areas) and have a comprehensive understanding of the negotiation, the possible decisions and the key levers that influence it.

- $\quad$ Executing GT based negotiations are worth only for important procurement categories (in terms of purchasing volume) since it is necessary to have support from expert and requires a long preparation work.

This research has also shown its novelty by presenting insights into the design of a GT based supplier selection process for bargaining and the evaluation of its impact on the effectiveness of the supplier selection process. The literature review showed that there is a lack of field studies utilising game-trees and backward induction that present the design and execution of a game (supplier awarding/selection) together with practitioners.

This work has therefore two main contribution:

1. Proving that the application of GT, namely by gametrees and backward induction for bargaining, can have a profound influence in increasing the effectiveness of the supplier selection process. The study of a real-world bargaining case has enabled the researchers to respond the calls for further empirical research in the application of GT for negotiation and bargaining (Tassabehji, 2010), as well as to tackle the need for providing more theoretical insights and managerial implications in the buyer-supplier relation (Maestrini et al. 2016). The empirical research can also help the refinement of existing theories and resulting consequences (Mithas and Jones 
2007; Hawkins, Randall, and Wittmann 2009) as it has tested the outcome predictions of GT models. It has been also introduced how the design of more effective selection processes can be integrated into their procurement strategies for improving firm's performance (Weele and Raaij 2014), by e.g. using strategic portfolio analysis (Kraljic in our process) and its strategic choices per quadrant, and linking it with the supplier selection process evaluation by means of game-theory.

2. Extending the knowledge on how GT principles can be applied to enhance the outcomes of the supplier selection process by understanding how game-trees and backward induction for bargaining are used. This work has described and justified the characteristics chosen to design the supplier selection process - which has not been extensively covered in the previous literature (Mithas and Jones 2007; Wyld 2011). By providing detailed insights on the how of the GT model for supplier selection and discussing the why for choosing specific game design parameters, this work can contribute towards a better understanding of the supplier selection design theory by means of GT. In other words, the ability to predict a bargaining result (depending on the hows and being aware of the whys) can be a powerful mechanism to support practitioners in their continuous search for more effective supplier management processes.

Regarding the applicability of the findings in other situations, it is necessary to point out that Action Research is by nature specific to the context of action and does not look for creating universal knowledge (Coughlan and Coghlan 2002). Anyhow, to understand the implications of the findings in other contexts should be taken into account (Eden and Huxham 1996; Coughlan and Coghlan 2002; Coghlan and Brannick 2014). Researchers are confident that our fivestage process (presented in figure 1) can be put into practice in other organisations and sectors in their supplier selection processes after careful consideration of the appropriate strategies for the particular purchasing category (Kraljic, 1983). The bargaining game characteristics could be influenced by the organisational context and the specific nature of each supplier selection process, therefore additional works from other procurement categories, companies and sectors would enrich the discussion of the applicability of our five-stage process. The research team have embarked on a wider research project to extend the application of that process in the automotive, household appliances and civil engineering sectors.

Regarding the research rigour, researchers have put into practice several tactics within the Action Research for ensuring validity of the study: the development of a research process, the creation of a research team, enacting the action research cycle continuously, and to subject assumptions to public testing. The interviews, data, observations and findings had been structured, documented and reported for discussion with the case company. Data collection instruments were utilised during the different phases of the research (interviews, database analysis, participant observation, feedback sessions, and informal discussion) to make possible the comparison and contrast findings at different stages of the project.

Even though this work has been focused on how to apply GT tools (game-trees and backward induction) for bargaining purposes, the researchers consider that this case also represents an interesting observation of how to respond to dominant suppliers in negotiations. This response to dominance has not been the main purpose for this work but the extension of the research from this angle may provide interesting insights for practitioners, including how the product engineering and purchasing management can work together to weaken the dominance of supplier by redesigning products or changing specifications.

\section{References}

Börgers, Tilman. 2015. An Introduction to the Theory of Mechanism Design Oxford University Press, USA.

Chaturvedi, Aadhaar, Damian R. Beil, and Victor Martínez-de-Albéniz. 2014. "Split-Award Auctions for Supplier Retention." Management Science 60 (7): 1719-1737.

Coghlan, David and Teresa Brannick. 2014. Doing Action Research in Your Own Organization Sage.

Coughlan, Paul and David Coghlan. 2002. "Action Research for Operations Management." International Journal of Operations \& Production Management 22 (2): 220-240.

Dixit, Avinash K. and Susan Skeath. 1999. Games of Strategy. New York: Norton.

Dutta, Prajit K. 1999. Strategies and Games: Theory and Practice. Boston, MA: MIT Press.

Eden, Colin and Chris Huxham. 1996. "Action Research for Management Research." British Journal of Management 7 (1): $75-86$.

Gelderman, Cees J. and Arjan J. Van Weele. 2003. "Handling Measurement Issues and Strategic Directions in Kraljic's Purchasing Portfolio Model." Journal of Purchasing and Supply Management 9 (5): 207-216.

Gelderman, Cees J. and Arjan J. Van Weele. 2005. "Purchasing Portfolio Models: A Critique and Update." Journal of Supply Chain Management 41 (3): 19-28. 
Handfield, Robert B. and Steven A. Melnyk. 1998. "The Scientific Theory-Building Process: A Primer using the Case of TQM." Journal of Operations Management 16 (4): 321-339.

Hawkins, Timothy G., Wesley S. Randall, and C. Michael Wittmann. 2009. "An Empirical Examination of Reverse Auction Appropriateness in B2B Source Selection." Journal of Supply Chain Management 45 (4): 55-71.

Hsin Chang, Hsin, Yao-Chuan Tsai, and Che-Hao Hsu. 2013. "E-Procurement and Supply Chain Performance." Supply Chain Management: An International Journal 18 (1): $34-51$

Huang, Samuel H. and Harshal Keskar. 2007. "Comprehensive and Configurable Metrics for Supplier Selection." International Journal of Production Economics 105 (2): 510-523.

Kasanen, Eero, Kari Lukka, and Arto Siitonen. 1993. "The Constructive Approach in Management Accounting Research." Journal of Management Accounting Research 5: 243 .

Kraljic, Peter. 1983. "Purchasing must Become Supply Management." Harvard Business Review 61: 109.

Krause, Daniel R., Mark Pagell, and Sime Curkovic. 2001. "Toward a Measure of Competitive Priorities for Purchasing." Journal of Operations Management 19 (4): 497-512.

Maestrini, Vieri, Davide Luzzini, Abraham B. Rami Shani, and Filomena Canterino. 2016. "The Action Research Cycle Reloaded: Conducting Action Research Across Buyer-Supplier Relationships." Journal of Purchasing and Supply Management 22 (4): 289-298.

Mithas, Sunil and Joni Jones. 2007. "Do Auction Parameters Affect Buyer Surplus in E-Auctions for Procurement?" Production and Operations Management Vol. 16 (4): 455-470.

Monczka, Robert, Robert Handfield, Larry Giunipero, and James Patterson. 2008. Purchasing and Supply Chain Management Cengage Learning.

Osborne, Martin J. and Ariel Rubinstein. 1994. A Course in Game Theory. Boston, MA: MIT press.

Perry, Chad and Ortun Zuber-Skerritt. 1992. "Action Research in Graduate Management Research Programs." Higher Education 23 (2): 195-208.
Schoenherr, Tobias, Sachin B. Modi, W. C. Benton, Craig R. Carter, Thomas Y. Choi, Paul D. Larson, Michiel R. Leenders, Vincent A. Mabert, Ram Narasimhan, and Stephan M. Wagner. 2012. "Research Opportunities in Purchasing and Supply Management." International Journal of Production Research 50 (16): 4556-4579.

Spina, Gianluca, Federico Caniato, Davide Luzzini, and Stefano Ronchi. 2013. "Past, Present and Future Trends of Purchasing and Supply Management: An Extensive Literature Review." Industrial Marketing Management 42 (8): 1202-1212.

Susman, Gerald I. and Roger D. Evered. 1978. "An Assessment of the Scientific Merits of Action Research." Administrative Science Quarterly: 582-603.

Tassabehji, Rana. 2010. "Understanding E-Auction use by Procurement Professionals: Motivation, Attitudes and Perceptions." Supply Chain Management: An International Journal 15 (6): 425-437.

Van Weele, Arjan J. 2009. Purchasing and Supply Chain Management: Analysis, Strategy, Planning and Practice Cengage Learning EMEA.

Vignali, Claudio and Mike Zundel. 2003. "The Marketing Management Process and Heuristic Devices: An Action Research Investigation." Marketing Intelligence \& Planning 21 (4): 205-219.

Webster, Jane and Richard T. Watson. 2002. "Analyzing the Past to Prepare for the Future: Writing a Literature Review." MIS Quarterly: xxiii.

Weele, Arjan J. and Erik M. Raaij. 2014. "The Future of Purchasing and Supply Management Research: About Relevance and Rigor." Journal of Supply Chain Management 50 (1): 56-72.

Westbrook, Roy. 1995. "Action Research: A New Paradigm for Research in Production and Operations Management." International Journal of Operations \& Production Management 15 (12): 6-20.

Wyld, David C. 2011. "Current Research on Reverse Auctions: Part I-Understanding the Nature of Reverse Auctions and the Price and Process Savings Associated with Competitive Bidding." International Journal of Managing Value and Supply Chains 2: 1-15.

Yigin, I. H., H. Taşkin, I. H. Cedİmoglu, and B. Topal. 2007. "Supplier Selection: An Expert System Approach." Production Planning \& Control 18 (1): 16-24. 